\title{
University Library Orientation By Television
}

\author{
BY EDWARD G. HOLLEY AND ROBERT W. ORAM
}

Ce CAN INSTRUCTIONAL TELEVISION solve

$U$ the problem of library orientation for large numbers of students?" This is one of the questions which many librarians in larger colleges and universities are beginning to ask themselves as they face the task of coping with increasing enrollments. For most institutions of considerable size the time has passed when individual class lectures and guided library tours provide adequately for library orientation. When one speaks of first-time degree-credit students, five to ten thousand of them in fourteen institutions, or even of three to five thousand students in thirty institutions, ${ }^{1}$ it becomes fairly obvious that a more effcient means of familiarizing these students with the library must be found than the traditional method of conducting students through the library in groups of twenty to thirty at a time. Moreover, there are numerous institutions with first-time degree-credit enrollments of one to three thousand which will undoubtedly double or triple their enrollments in the next five to ten years. Some institutions are already overwhelmed by trying to provide even a basic introduction to library services, and content themselves with offering each entering student a library handbook and bidding him Godspeed.

The problem of orientation is highlighted at an institution like the University of Illinois, which has both a large total enrollment and a sizeable complex of colleges and schools whose library needs are supplied by an equally extensive library system (over three million

1 U. S. Office of Education. Educational Statistics Branch. Opening (Fall) Enrollment in Higher Education, 1961: Institutional Data (Washington: Govt. Print. Off., 1961).
Mr. Holley became Director of Libraries, University of Houston, Texas, early in the summer of 1962. He had been Librarian of the Education, Philosophy, and Psychology Library at the University of Illinois Libraries, Urbana. Mr. Oram is Circulation Librarian at Illinois.

volumes in some thirty-four separate locations). Prior to 1961 , most orientation for freshmen took place through means of the personally conducted library tour. There was a general tour for students in the beginning English course (Rhetoric 102) and, in addition to this basic introduction, some departmental librarians serving the various professional colleges provided instruction in library use for their specific fields-occasionally in formal courses and upon invitation from specific faculty members, but more often through personally conducted tours of their own special libraries.

In the case of the education, philosophy, and psychology library, the librarian and his assistant provided tours for three hundred and fifty to five hundred students in Education 101 (the basic introductory course), for forty to eighty students in some sections of Education 240 (the methods course), and for one hundred to a hundred and fifty students in the children's literature courses offered by the graduate school of library science, a minimum total of some five hundred students per semester.

The amount of staff time spent on these tours, plus the time the librarians devoted to more formal lectures, began to be a serious burden, to say nothing of the limitations in effectiveness when a staff member has delivered fifteen lec- 
tures a semester on the same subject for the last ten years.

The problem of orientation for all incoming students, particularly those in rhetoric or similar courses in the division of general studies, was much the same as that for the college of education, although general orientation had to cover a larger physical area and had to be both more general and, in some ways, just as specific. The tours of the main library building had always been directed at students writing term papers in rhetoric; no tours were offered for any other groups unless an individual instructor wished to conduct a tour of his own. Professional librarians from the reference department and the undergraduate library gave the rhetoric tours, which took fifty minutes, a large part of which was devoted to moving groups of twenty to twenty-five students from one place to another in a building which covers the better portion of a block. Often the students ended the tour by being more familiar with the corridors than with the card catalog. Although the tours did have the advantage of giving the student a feeling for the physical arrangement of the building, even though his attention might wander if he were on the fringe of the group, the tours were highly unsatisfactory from a library viewpoint. Large blocks of staff time were involved, only half the rhetoric instructors took advantage of the opportunity, the tours disturbed other students studying or using the card catalog, and it was often difficult for all members of any one group to see the cards in the tray or even the large mockups used. Sometimes the size of the group and the height of the rooms prevented even the strongest-voiced librarian from being heard properly.

Under these circumstances, many librarians came to question the effectiveness of an operation so time-consuming and so obviously ineffective. As increasing enrollment compounded the problems, it was apparent that the small, well-organized, personally conducted tour had outlived its usefulness. In the fall of 1960 a number of interested staff members visited Illinois State Normal University in Normal to observe their experimental orientation program using television as the medium, and to see if there might not be implications for a much larger and more complex university. ${ }^{2}$

Although the group was impressed with the program at ISNU, they generally believed that TV facilities at Urbana might call for a different type of program. Initially, the library could experiment with one unit, learn from the mistakes, and possibly eventually develop a comprehensive program of library orientation by television.

The need for a better orientation program was discussed formally in the College of Education Library Committee for the better part of a year. While the committee believed that orientation was needed at all levels, e.g., undergraduate, graduate, and faculty, no one program would be likely to serve all groups equally well, and the undergraduates certainly constituted the most pressing problem. Many students coming to Illinois for the first time were completely bewildered by the size and complexity of the library system, and from their first frustrating contact resolved to have as little to do with the library as possible. The unusual student doggedly persisted until he knew his way around the system and could find what he wanted. Neither attitude was conducive to adequate preparation for teachers. To discover what kind of program would serve student needs most effectively, the committee sought answers to these specific questions: when does the student need orientation most, upon what course should the program be built, and through what medium can such orientation most efficiently be provided? Other faculty members, librarians, and students themselves were queried in an attempt to find the answers. While various points of view were ex-

2 This program is described in "TV Library Instruction," Library Journal, LXXXVI (January 1, 1961). 
pressed, the tendency seemed to be to use $\mathrm{TV}$ in preference to film, personally conducted tours, or handbooks. The course which provided the logical basis for experimentation was Education 101, an introductory course. After discussion with the office of instructional television and upon the offer of Charles J. McIntyre to assist in the program, the committee decided to go ahead with a video tape. Once the program had been taped, it could be rerun as many times as necessary, and production costs were definitely lower than those of film. A subsidiary advantage, which later proved illusory, lay in the coordination of the library orientation program with the general university-wide use of instructional television for orientation.

Once the decision had been made, the Education Library Committee drew up a complete list of what was to be included in the program, including the format, the number of photographs of the library, etc. On one point the committee was clear: the program should include certain very specific types of information and concentrate upon these rather than give the student a panoramic view of everything in the library. Particular attention should be given to the reserve book system, use of the card cata$\log$, and instruction in the three basic reference tools in the field of education: Education Index, Buros' Fifth Mental Measurements Yearbook, and the Encyclopedia of Educational Research. Subsidiary information might be presented upon special materials such as periodicals, curriculum publications, and educational and psychological tests, but the main emphasis (subsequently reinforced by various devices throughout the actual program) would be on location data and the three reference tools. To assure this essential focus, the program was framed with only the needs of Education 101 students in mind, though the committee recognized that the program might be useful for other classes as well.

In the summer of 1961, the librarian narrated a 39-minute tape, "Education Library Tour," incorporating the above suggestions. Although the tape was filmed in the TV studio, ample provision had been made for the introduction of slides and diagrams showing the actual parts of the library, the various procedures for checking out books and locating data, and other devices demonstrating items the student would probably use in this library. Since the office of the dean of students was working on a general orientation program for freshmen at the same time, the committee agreed to give the program its trial run in that framework. To provide the proper introduction and stimulate interest, the dean of students, Fred H. Turner, and the dean of library administration, R. B. Downs, taped a six-minute preview to the main program. On September 26, 1961, "Education Library Tour" was broadcast over the university's television station, WILL-TV, for the first time. All organized houses and dormitories had set up stations to receive this and other programs in the general orientation series and had provided specially designated students as discussion leaders for each program.

Prior to the broadcast the librarian met with the instructors of the various sections of Education 101 to discuss ways in which they could make the orientation program more effective by emphasis on its main points before the program and a follow-up project afterwards. As a rough measure of the tape's effectiveness, each student who viewed the program was to be given the same simple tenquestion quiz which had been given to students who took the tours the year before. Thus there would be some basis for comparison of the two methods of orientation, though such test results could obviously not be interpreted too strictly.

Although the test results were not spectacular, they did reveal that the students had at least obtained as much information from the tape as they had 
from the tours. Furthermore, it was the general consensus that this program on a specialized library had suffered from its inclusion within the framework of general university orientation. House conditions were not always favorable to attentive viewing, the confusion of large groups made retention difficult, and a number of students reported difficulty in seeing the program at all. Criticism and comments from both faculty and students favored broadcasting "Education Library Tour" to specific class sections during the second semester. Despite some mechanical difficulties and the need to improve certain technical details in the tape, all agreed that the program was worth continuing. The revision of the tape could await further trial under different conditions with the expectation that the revised program could be undertaken in the summer of 1962.

Since the library staff was in agreement with the judgment of faculty and students, Dean Downs appointed a committee composed of the circulation librarian, the reference librarian, and the undergraduate librarian to develop a TV program providing a general introduction to the entire library system. This program could replace the rhetoric tours and might well serve as a basis for a subsequent series of programs for the specialized libraries.

The new committee viewed the education library tape and agreed that the TV presentation was a satisfactory solution to the problem of communicating details of library routines to large groups of students. This committee believed the ideal solution would be a complete sound-track movie, but the complications involved in such a program, plus the expense, made such a step impossible, at least until an experiment with TV tape had been made. The education library tape was a good learning device for this committee, and without it more time would have been wasted in experimentation, both by the librarians and the
TV production personnel. Nonetheless, the format did not seem to fit too well the general orientation picture. Designed as it was for a very special audience, the "Education Library Tour" had used the librarian as a sort of host-narrator who was seen as well as heard. When the camera was not focused on a title-page, catalog card, or slide of the library, it was directed to the narrator. The committee decided to abandon this format in favor of an unseen narrator. The camera could, under the new proposal, always be on the title or the card or the index being discussed. Moreover, the committee decided to use as many motion shots as possible with a silent camera. These shots would substitute for the physical presence of the student, avoid confusing floor plans, and help pinpoint locations.

For this new tape, a definite time limit of 30 minutes was suggested to conform to the over-all orientation program. Presumably, the same material which had been presented in the tours could be condensed if there were no problem of moving students from one spot to another. Later this proved to be a false assumption since the committee found itself adding more material in order to give depth. The program covered the same area as the tours had covered and had to be designed so that it gave orientation not only to rhetoric students but to any other group of potential users. This marriage of the specific and general, the simple and the complex, had its drawbacks and later led to some student complaints that it was too slow for those who knew the library ${ }^{3}$ and was much too compressed for those who had never seen a library of the complexity of Illinois. The latter criticism was countered by providing a previously prepared handbook, Your Library, to every undergraduate. Since the TV program was viewed as a supplement to the handbook, the

3 "Insulted the intelligence" was a common statement; this statement was also made about the education library tape, but less frequently. 
script referred to the handbook several times and assured the students that any details missed in the film could be found by an investigation of this booklet.

To give continuity to the tape, the committee decided to use one subject as its basis and carry this subject throughout the program. The subject, "Space Flight," proved an appropriate one since the first showing of the program coincided with the John Glenn orbit. The program was designed to begin with the general, (the card catalog) and progress to the specific (circulation desk routines, reference department materials, and undergraduate library routines). All three librarians worked on sections of the program but the final draft was edited by one person for the sake of continuity. Areas stressed by the committee were the university's main card catalog, the Reader's Guide, and other reference materials which provided keys to the material on "Space Flight."

Once the committee had finished its task and the program had been approved, it was submitted to the rhetoric department for suggestions. Aside from stylistic corrections, the main objection was that the script was library-centered rather than rhetoric-centered, an objection mitigated by showing the student how to transcribe library information on cards in correct bibliographic form. The script was then submitted to TV production personnel to make the necessary 181 slides and 130 feet of film.

The program, "Your Library," was broadcast on March 13 and 14, again within the framework of general university orientation. As had been true of the education library program, there were many problems: bad listening conditions, confusion caused by large groups and inability of individual instructors to follow up the program. Presumably, with closed-circuit TV, as had been used at Illinois State Normal University, initial student response would have been better. Again, the program itself was not an issue, but rather the scheduling and technical problems which can be overcome.

In general the rhetoric department was favorably impressed with the program's potential. The head of the Rhetoric 102 sections, who had initially been skeptical about the replacement of the tours, agreed that points were made more forcefully by $\mathrm{TV}$ than they could have been made by tour. Perhaps the most justifiable criticism was that too much material was covered in too little time. Possibly a longer program or a series of programs would do a more effective job. The rhetoric department still favors a progrram designed specifically for the student doing a reference paper in which library orientation is only incidental. Such a program could easily be prepared by using the materials already gathered for the library's program, although it is the library view that such a program is a rhetoric department responsibility. No statistical data is available on the results of "Your Library," but there is general agreement that the program was well worth the effort and does as effective a job as the tours did. From the viewpoint of the library such an orientation program is definitely needed, and "Your Library" is a good first step.

What of the evaluation of the first program, "Education Library Tour?" Shortly before "Your Library" was completed, students in Education 101 again had an opportunity to evaluate "Education Library Tour." Again a ten-question test was given and again, although the results showed some slight improvement, the tape was demonstrated to be only as effective as the tours. The following table indicates the comparison of test results for tours and TV program for the education library.

In using these results one should real. ize that they are at best a rough estimate. No control groups were set up and no thorough analysis of the different sec- 


\begin{tabular}{|c|c|c|c|}
\hline . & $\begin{array}{c}\text { Tours } \\
\text { (Spring, 1961) }\end{array}$ & $\begin{array}{c}\text { TAPE } \\
(\text { Fall, 1961) }\end{array}$ & $\begin{array}{c}\text { TAPE } \\
\text { (Spring, 1962) }\end{array}$ \\
\hline $\begin{array}{l}\text { No. Students } \ldots \ldots \ldots \ldots \ldots \ldots \ldots \ldots \\
\text { Range } \ldots \ldots \ldots \ldots \ldots \ldots \\
\text { Right responses } \ldots \ldots \ldots \ldots \ldots \ldots \ldots \\
\text { Wrong responses } \ldots \ldots \ldots \ldots \ldots \ldots\end{array}$ & $\begin{array}{l}456 \\
0-88 \\
62 \text { per cent } \\
38 \text { per cent }\end{array}$ & $\begin{array}{l}444 * \\
0-100 \\
65 \text { per cent } \\
35 \text { per cent }\end{array}$ & $\begin{array}{l}304 \\
0-100 \\
66 \text { per cent } \\
34 \text { per cent }\end{array}$ \\
\hline
\end{tabular}

* Includes 56 students who took test but did not see program.

tions was made. Although the results fall short of expectations, they do provide some encouragement. The least that can be said is that the same amount of information is communicated with the expenditure of much less effort. With improvement in techniques and with a more careful analysis of student needs, the library should be able to prepare more effective programs and secure even better results.

One special comment can be made about test results from Education 101: the secondary education sections performed better than the elementary sections. Since the former group consists largely of sophomores and juniors who are expected to know their way around the library, while the latter group consists largely of freshmen, the question arises as to how well the program met the library needs of the incoming freshmen. However, a number of graduate assistants who led the discussion groups after viewing the film commented that the students appeared to learn more from the program than their test responses indicated. They also volunteered the opinion that the students might have been better prepared if they, as the instructors, had previewed the program first. Such comments reveal that much better coordination between class and library will be needed to achieve maximum results.

In an attempt to determine why one class was conspicuously successful in terms of test results, the education librarian met with students in that class to elicit their comments and criticisms. The students were candid and cooperative. Much of the discussion centered upon the technical details (blurred images, poor shots of books, pages, etc.) and poor scheduling; some questioned the necessity for including basic data such as an explanation of the card catalog in the video tape. Others, however, found this section very useful and wanted it retained. While there was no agreement on what could be left out, the class did agree on one point: there should be further library instruction in the use of specific reference works as had been done with Education Index, Buros' Fifth Mental Measurements Yearbook, and the Encyclopedia of Educational Research.

From the comments, test results, and general library evaluation it is apparent that the basic outline of the Education Library Committee stood up well. Many of the criticisms were concerned not with the substance of the program but with details which can be improved, either by revision of the programs in their entirety, or by splicing in better sections. Such problems as scheduling at the right time can be overcome during the coming year when the university will have more closed circuits available and more classrooms equipped to receive such broadcasts. Viewed in the total framework of library orientation, the year's efforts have been fruitful. With more refinement of the program there seems to be no reason why orientation by television cannot be made an effective and efficient part of the university's total instructional program.

After a year of rather intensive work with library orientation, the authors of this article submit the following comments for whatever help they may be 
to others who contemplate similar programs:

1. Television does hold good promise of orienting large groups to the library successfully.

2. There are no technical details which cannot be met by adequately planning the use of this medium. Indeed, in terms of explaining the catalog and certain reference books, this medium is superior to the ordinary personally conducted tour.

3. There are, however, difficulties involved in determining the best procedures and the best approaches for each university and each specific class.

4. Some of the questions which each librarian must answer for himself are:

A. What specific data do I want to communicate? Location data? How to use the card catalog? How to use specific reference works? How to write a term paper? No program can do everything.

B. Within the framework of what specific courses do I want this library program to fit? The basic English course? The basic education course? The advanced undergraduate course?

C. What techniques can most effectively communicate procedures by TV? Slides? Movies? Mockups? Narrator-lecturer?

D. In terms of cost is the closed circuit TV the most economical method of library orientation?

If the answer to these questions is that TV orientation is a particular library's solution, then one or two other major points should be stressed here. Sufficient time should be allowed for adequate planning, writing, and production. Assuming that the entire production, other than the purely technical aspects, is to be done by people who are untrained in script writing, a year is not too long to prepare a finished script from its committee and planning stage until it is filmed. It is also wise to consult with the TV production staff several times before the final script is prepared. They may be able to offer advice which can save time.

\section{UNESCO Regional Seminars}

Three regional seminars convened during September and October by UNESCO and a government of each region, for the purpose of furthering library service in developing countries within the framework of national economic development and educational programs.

A regional seminar on cooperation between libraries and documentation centers in Arab countries met at Cairo, October 15-27. On September 24 to October 5 a regional seminar on the development of university libraries in Latin America convened at Mendoza, Argentina. On September 10-22, the development of libraries in Africa was studied at Enugu, Nigeria, with the library established by UNESCO in 1953 as a demonstration center. 